Print ISSN: 2233-4165 / Online ISSN: 2233-5382

doi:http://dx.doi.org/10.13106/ijidb.2018.vol9.no4.43.

\title{
Effects of Taxi-Booking Apps of E-Service Quality on Use Intention in China
}

\author{
Zhong-Bo, Guo*, Uk-Yeol Park**, Jong-Ho Lee*** \\ Received: March 15, 2018. Revised: April 1, 2018. Accepted: April 15, 2018.
}

\section{Abstract}

Purpose - The purpose of this article is to examine the effects of perceived value, satisfaction, and continued use intention of e-service Quality of taxi-booking apps.

Research design, data, and methodology - The questionnaire was created to examine every relevant variables to practical and theoretical implications. The pilot survey was conducted for 15 days from April $7^{\text {th }}$ to April $21^{\text {st }}$ in 2016 . Their total numbers were 354 surveys. But 330 copies were used for the analysis except 24 of them. To make a more effective analysis, several analysis tools and analysis programmes were used, such as IBM SPSS and AMOS.

Results - The results are as follows. First, all variables of e-service quality except safety make influences on perceived value. Second, e-service quality except safety makes influences on satisfaction. Third, perceived value makes influence on satisfaction and on intention of continued use. Fourth, satisfaction makes influence on intention of continued use.

Conclusions - First, 5 variables are very limited. more valuable variables are need to test with this model. Second, this study was conducted only in China. So there may be possible to the representatives. To use this model for better analysis and application abroad, more characteristics and strategic factors should be considered like the local culture of a particular country, attributes for different environment etc.

Keywords: Taxi-Booking Apps, e-Service Quality, Perceived Value, Satisfaction, Intention of Continued Use.

JEL Classifcations: M11, M31, N70.

\section{Introduction}

Within the $21^{\text {st }}$ century, life has so much changes amazingly. Our lives had become better than before, unprecedently marching towards the betterment of society as new creation meets innovation, sparking a new experience. Unvaried to other elements in life, the development of technology had impacted and redefined how business runs, raging more profits than ever before, yet skyrocketing the sales figures to new records.

The legacies, given to us by these inspirators, innovators, insignificant individuals of history all began with questions encapsulated in their mind like, can I make this better with the development of mobile apps including IT? It is the

* First Author, Master of E-Commerce, Dept. of Electronic Commerce, Kongju National University, Korea.

Tel: +82-41-850-8255, E-mail: guo_0321@naver.com

** Co-author, Ph.D. student, Dept. of Electronic Commerce, Kongju National University, Korea.

Tel: +82-2-861-8672, E-mail: puy1219@naver.com

*** Corresponding Author, Professor, Dept. of Electronic Commerce, Kongju National University, Korea.

Tel: +82-41-850-8257, E-mail: leejh@kongju.ac.kr reason why that widespread of recent communication technology can lead mobile industry(Kim, 2011; Kim et al., 2016; Shao et al., 2017). Better has driven innovation and re-made our questionable imagination into significant life improvement unit. Thus, with my passion for the convenience of travelling and my love for enjoying the surrogate driving experience, revolutionizing the taxi-call industry had been the primary goal of my research topic. Kicking off with meticulous and comprehensive effort.

The purpose of this article is to examine the effects of perceived value, satisfaction, continued use intention of e-service Quality of taxi-booking apps. As known by all, the smart phone industry had uprised and uproar since the introduction of game changing phone in to the market, the Apple iphone 3G, phones and business related industries had utilized such digital telecommunication platform to wide-stretched their business.

\section{Theoretical Background}

The phone, which once conventionally be defined as a tool to communicate, can now be redefined as a tool to 
communicate for a particularly purpose in various effective yet smart ways. The term "APP" is a simplification term of "Application Software". Originally, "mobile app" ("Apps" used on mobile; from here upon, known as mobile app) was initially launched for basic productivity and retrieving information, like email, contacts and messages. This indirectly investigates a new challenge, branching out to media information sharing (blogs, magazines, news etc), business goods \& service providing (Gmarket, Samsung Taobao), daily task operations assisting tools (online classes tools - Coursera, Spreadsheets, Maps) and more.

Just like any business, the conventional taxi-booking business heretofore was confined to phone lines or calls. However progressing from introduction of its service platform on the World Wide Web. Taxi-app had born in the era of smartphones.

Taking the current market progression into consideration, a differential segment of e-market, e-service had revolutionized the business industry, the taxi-booking apps. Videlicet, the standard and the guidelines of research would encircle the effects of perceived value and satisfaction on the intention of the continued use. As firms competition are getting more vigorous in order to be a dominant player in this oligopoly market, significant researches are needed on the characteristics and affecting factors, taxi-booking apps. Therefore, this research on the effects on perceived value and satisfaction on continuous use intention of taxi-booking apps would provide useful information to firms.

\section{Major Variables}

\section{1. e-service quality variables}

This research will primarily focus on the characteristics of intention for continued use of the taxi-booking apps's e-service which get the effects of perceived value and the effect of satisfaction. So the characteristics are as follows:

(1) reactivity (2) reliability /trustworthiness (3) safety / security

(4) conveniency (5) instant connectivity.

Above attributes of e-service of taxi-booking apps that are aligned with the research positive result could be implied via this research to present the key factors that could be further utilized in business strategy planning. This will in turn further leverage the continuous use intention of e-service quality by taxi-booking apps.

The concept of e-service by taxi-booking apps. Conventionally, calling a cab can be a fussy and long process as the operator phone lines night be busy and in queue during peak hours. Not unless a particular firm invest more in its general telephone line number(infrastructure), the process is simple but frustrating for those who are in queue and hurried. With a revolution on communication in this digital era, we now can inform one firm/individual with regards to our demand for a service via a platform or better known as digital impulse that could be interpreted. From the bulky desktop to a small hand-size electronic device called smart phones, mobile app plays a critical networking tool for customers to interacts with business firms in the cab or taxi industries.

A passenger who needs a cab service want to find a vacant cab just around the corner, on a curb within a short time and yet booked the cab if the cab driver is willing to provide its service at that particular time. When the cab arrive, the passenger gets on and departs to destination recorded via the app. The passenger only pays either in physical cash or digital transfer of payment to the cab driver at the end of the service provided by the cab driver.

As above mentioned, the characteristics are to be summarized as below: (1) reactivity (2) reliability / trustworthiness (3) safety / security (4) conveniency (5) instant connectivity.

\subsubsection{Reactivity}

Nowadays, in Korea, it is very popular for passenger to use taxies with taxi-booking apps(in other words, taxi-calling apps, taxi apps, mobile taxi apps etc.)

Based on this research paper, Taxi Service can be defined as firm/service provider utilizing a mode of vehicle (taxi) to transfer their customers quickly(Kang, 2008). The function of taxi-booking apps is to send the customer from the pick-up point to the destination with safety and quickest route. Daily taxis' operations cover booking/reservation, delivering, cab internal services and other directly or indirectly related services when a customer use such services and make a payment for it.

Thus, focusing on the definition of reactivity, it means that how the taxi provides service(driver/firm response) to the customer demand; namely, how the customer response towards the taxi service expect to provide it. The taxi driver can fulfill the customers' demand by the type of taxi and its service.

\subsubsection{Reliability / Trustworthiness}

The taxi driver's service can improve their service quality and users satisfaction, via sampling, responsiveness, assurance, consensus and class(Kang, 2008). These several factors are major ones to reliability/trustworthiness. Reliability or better known as trustworthiness became a determinant factor. Relating this to the taxi industry, a company's portfolio and reputation keeps a key factor on determining how many customers may take. This may include its effectiveness, speediness, drivers virtue, cost charges for its services and conditions of its cab etc. Only with trust or to be a reliable company, a client would then be willing and be in full trust to utilize the particular company's providing service either offline or online and pay when the service provided are promised as claimed and attained full satisfaction for what he or she perceived its value. This is 
also to mean, comparing the conventional method and such new innovative method of e-service, there should be an advancement of service or a discounted rate to encourage user to use yet nothing change backwards in terms of service quality or incurring any additional charges for inappropriate conveniency. Back to basic relationship, trust is the basic of all relationship, thus, with no dispute, such e-service of taxi-booking apps.

\subsubsection{Safety / Security}

According to recent news, our security had been threatened via various perspective, online and offline, and in various sector of industries. With the conveniency of internet, it also encapsulates some vulnerability. When a user uses the mobile banking e-service, he or she is first required to register some personal information and required information to use it. However, such vulnerable information, if fallen to wrong hands, can take into the risk for the user as the user safety is able to make an influence both directly and indirectly. Mobile apps such as mobile banking and taxi-booking apps are both open to be attacked as their operating system runs on a much simpler yet less protected platform due to its infancy stage. Via mobile banking, PIN (Personal Identification Number), Account number, Secret code, and other personal information are then exposed to risk and vulnerable to be used by hackers for the infringe benefit for immoral ethics. Thus, users would suffer from not just physically loss but also mentally in terms of stress, worries and fear. Especially, this variable is very important one as mobile, apps etc. make development by $\mathrm{Wu}$ et al. (2016, 2017).

\subsubsection{Conveniency}

Conveniency, a primary key drive to innovation, shapes our lives for a better life and leads a much comfortable one. $\mathrm{Li}$ et al.(2017) insisted that point in their research. This was profoundly defined, allowing customer to feel more comfortable or much more relieve when using a service or in the process of experiencing a service(Venkatesh \& Davis, 1996; Davis, 1989). Moreover, after researching mobile internet service(herefrom on e-service) loyalty, its loyalty rate is plainly based on the e-service after service satisfaction in(Lee, 2004). Thus, we can assume that e-service affects users in some kinds of ways, concurrently, becoming a determinant factor whether a particular e-service quality can expand. Conveniency, a simple phrase, perhaps can define as something that promotes comfort or advantage, freeing from trouble, commodiousness. Focusing such aspect on e-service, taxi-booking apps should be easy about the process or changing the state or quality of a service to pursue one's wants or accommodation in a more relevant way. For every degree of conveniency the quality plays an important role in taxi-booking apps.

\subsubsection{Instant connectivity}

As previously stated, conveniency can simply means easier or comfortable usage. One co-link factor to this is instant connectivity(Kim \& Kim, 2002). Instant connectivity is defined as mobile internet service that could be utilized by the user anytime, anywhere(Lee, 2004). Instant connectivity can utilize current positioning system which links with internet and provide feedback on the current position to the service provider, with the infrastructure, IS-95C, GPRS(Kwak \& Lee, 2005). Like the wide-spread of mobile banking, instant connectivity, promotes as well as enabling effective and efficient communication, immediate receipt, acknowledgement or reply between the service provider and service user. Such features overrides the time lag between communication method which are logged and lagged due to slow process, such as phone calls - there is a beep ringing, e-mails.

\subsection{Mediators}

\subsubsection{Perceived Value}

Perceived value is a branding catalyst and marketing tool to promote a product based on customer trust and their believe that a particular product or service meets their needs or suits their demands. Customers ultimately make the critical decision on how to interpret and react to such messages to understand this better, looking from the value proposition, the customer would compare the price he or she required to pay for the possible value. Serving as a guideline from looking on previous researchers works and the basic guidelines of trades, such values in the eyes of the consumer can be summarized to 4 categories : functional value, monetary value, social value and psychological value. <Table 1> presents the summaries of value definition to authors.

a) Functional Value:

What it can provide or offer to the customer, a solution or answer for customer needs, demands or even questions.

b) Monetary Value:

A trade-off between the possible benefits compared to what its offerings worth or paid in return for the function.

c) Social Value:

Engaging or attaining an ownership over a service or product yet allowing consumers to go beyond the conventional extend to interact with each other.

d) Psychological Value:

Emotional value or feelings that attributes to products or services experienced by consumers. In other words, it means that the extent of freedom which enable consumers to freely define their emotional value in any kind of way. 
$<$ Table 1> Summaries of value definition to authors.

\begin{tabular}{|c|l|}
\hline Research & \multicolumn{1}{|c|}{ Content } \\
\hline $\begin{array}{c}\text { Sweeney } \\
\text { Soutar } \\
(2001)\end{array}$ & $\begin{array}{l}\text { perceived value is classified into functional value, } \\
\text { emotional value, social value, monetary value etc. }\end{array}$ \\
\hline $\begin{array}{c}\text { Gallaeza \& } \\
\text { Saura } \\
(2006)\end{array}$ & $\begin{array}{l}\text { As a broad meaning, perceived value is defined } \\
\text { as sacrifices related consuming behavior and }\end{array}$ \\
\hline $\begin{array}{c}\text { Smith \& } \\
\text { Colgate } \\
(2007)\end{array}$ & $\begin{array}{l}\text { To examine the importance of the perceived } \\
\text { in society based on previous studies of social } \\
\text { science. }\end{array}$ \\
\hline $\begin{array}{l}\text { Lin \& } \\
\text { Huang } \\
(2012)\end{array}$ & $\begin{array}{l}\text { Overall consumer experience and green products } \\
\text { are defined by their purchasing behaviors related } \\
\text { to the conditional value concept as functional } \\
\text { value, social values, emotional and search value. }\end{array}$ \\
\hline
\end{tabular}

\subsubsection{Satisfaction}

From general dictionaries, satisfaction denotes as a happy or pleased feeling due to something that one experience or act of providing what is needed or desired. In business context, such as e-service, satisfaction exhibited by customer can be expelled as expectations of customer concerning an experience of a service or a product provided by a firm, enterprise or individual (better known as seller). It is a major concept and usually revolves around the quality of an service, which in this case, quality of the e-service of taxi-booking apps. Only by collecting and analysing customer satisfaction, it can leverage the intention of continued use. Overall, with satisfaction, one is willing and able to persist to use a particular e-service for the betterment meeting one's desire or needs. <Table 2> illustrates the contents of satisfaction.

<Table 2> The Contents of Satisfaction

\begin{tabular}{|c|l|}
\hline Research & \multicolumn{1}{|c|}{ Content } \\
\hline $\begin{array}{c}\text { Tse \& } \\
\text { Wilton }\end{array}$ & $\begin{array}{l}\text { As a norm related pre-expectation or outcomes on } \\
\text { products, the difference between perception and } \\
\text { expectation after consumption. }\end{array}$ \\
\hline $\begin{array}{c}\text { DeLone \& } \\
\text { McLean } \\
(2003)\end{array}$ & $\begin{array}{l}\text { A key role to measure the user's opinion with the } \\
\text { electronic commerce system and a measurement } \\
\text { including total processes for examples, information } \\
\text { extraction, service, purchasing, payments etc. }\end{array}$ \\
\hline $\begin{array}{c}\text { Sun } \\
(2005)\end{array}$ & $\begin{array}{l}\text { With subjective, cognitive measurement unit, and } \\
\text { alternative for financial system at system } \\
\text { effectiveness. }\end{array}$ \\
\hline $\begin{array}{c}\text { Cheong } \\
(2009)\end{array}$ & $\begin{array}{l}\text { Helpful scale for users on the quality of system } \\
\text { properties(service, cooperation, information, system). }\end{array}$ \\
\hline $\begin{array}{c}\text { Sin } \\
(2011)\end{array}$ & $\begin{array}{l}\text { Using hotel information system \& hotel financial } \\
\text { information system, the hotel is able to meet } \\
\text { customers or its registered members demand, } \\
\text { leveraging its credibility. }\end{array}$ \\
\hline $\begin{array}{c}\text { Chui } \\
(2015)\end{array}$ & $\begin{array}{l}\text { Cognitive evaluation in the process of information } \\
\text { service and emotional evaluation from outcomes } \\
\text { after using. }\end{array}$ \\
\hline
\end{tabular}

\section{Research Model and Hypotheses}

According to previous study, the research model was made as follows.

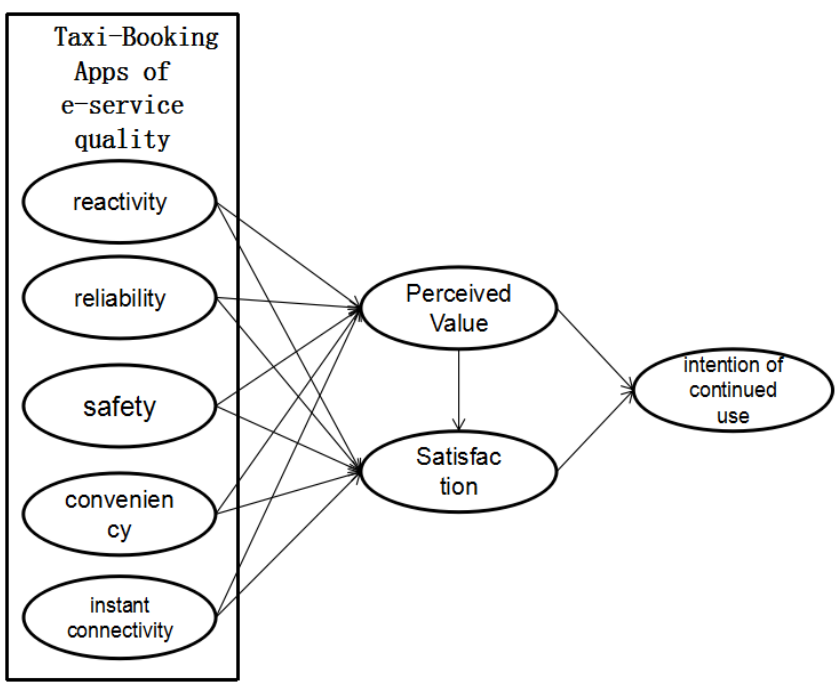

<Figure 1> Research model

According to research model, hypotheses were built as belows.

$<\mathrm{H} 1>$ e-service quality of taxi-booking apps will make the positive influence on perceived value.

$<\mathrm{H} 1-1>$ reactivity will make the positive influence on perceived value.

$<\mathrm{H} 1-2>$ reliability will make the positive influence on perceived value.

$<\mathrm{H} 1-3>$ safety will make the positive influence on perceived value.

$<\mathrm{H} 1-4>$ conveniency will make the positive influence on perceived value.

$<\mathrm{H} 1-5\rangle$ instant connectivity will make the positive influence on perceived value.

$<\mathrm{H} 2>$ e-service quality of taxi-booking apps will make the positive influence on satisfaction.

$<\mathrm{H} 2-1>$ reactivity will make the positive influence on satisfaction.

$<\mathrm{H} 2-2>$ reliability will make the positive influence on satisfaction.

$<\mathrm{H} 2-3>$ safety will make the positive influence on satisfaction.

$<\mathrm{H} 2-4>$ conveniency will make the positive influence on satisfaction.

$<\mathrm{H} 2-5>$ instant connectivity will make the positive influence on satisfaction. 
$<H 3>$ perceived value will make the positive influence on satisfaction.

$<\mathrm{H} 4>$ perceived value will make the positive influence on intention of continued use.

$<H 5>$ satisfaction will make the positive influence on intention of continued use.

1. To identify the extent to which there is a segmented approach in marketing activity especially for Pay per click marketing.

2. To establish how Pay per click marketing strategies is being used to reach, inform and influence online users.

\section{Empirical Test}

\subsection{Data collection}

To accomplish the goal and the objective, literature research and empirical research were conducted. According to previous researches on taxi-booking apps characteristics that have affected the continued use. A series of suppositions was established and modelled to testify it. In terms of research analysis subject, a series of questionnaire were distributed to a group of participants who had experiences using taxi-booking apps.

The questionnaire was carefully created to examine every relevant variables to practical and theoretical implications were discussed. The pilot survey was conducted for 15 days from April 7th to April 21st in 2016. with the help of Chinese questionnaire site, http://www.sojump.com. Their total numbers were 354 ones. But 330 copies were used for the analysis except 24 ones.

In the process, to make more effective analysis, several analysis tools and analysis programmes are used, IBM SPSS Statistics 21.0 and IBM SPSS AMOS 21.0. The method applied for this research covers hypothesis, reliability analysis, relationship analysis, validity analysis, and regression analysis with structural equation model.

\subsection{Demographic analysis}

The total numbers of questionnaire are 330 ones. Among them, 135 are males(40.9\%) and 195 are females(59.1\%). According to age, the 20's is 233 persons(70.6\%), 30's 33 persons(10.0\%), 40's 46 persons(13.9\%) and the 50's 18 persons(5.5\%).

In terms of their occupation, white collars are 125 persons(37.9\%) mainly. In case of income earned, below 1.0 million won is 137 persons $(41.5 \%)$, According to experience for using taxi-booking apps, over 1 month to 6 months is 84 persons $(25.5 \%)$, In case of waiting time, within 5 minutes is 170 persons $(51.5 \%)$ and next is within 3 minutes 119 persons(36.1\%).
At its use experience, 1-3 times is 124 persons(37.6\%) and 3-5 times 64 persons(19.4\%), 5-8 times 59 persons $(17.9 \%)$ respectively. <Table $3>$ shows the results of demographic analysis.

$<$ Table 3> The Results of Demographic Analysis

\begin{tabular}{|c|c|c|c|}
\hline \multicolumn{2}{|c|}{ Classifications } & $\begin{array}{l}\text { Respondent } \\
\text { (Persons) }\end{array}$ & $\begin{array}{c}\text { Percentage } \\
\text { (\%) }\end{array}$ \\
\hline \multirow{3}{*}{ Sex } & Male (M) & 135 & 40.9 \\
\hline & Female (F) & 195 & 59.1 \\
\hline & Total & 330 & 100.0 \\
\hline \multirow{6}{*}{ Age } & $10-19$ (y.o) & 0 & 0 \\
\hline & $20-29$ (у.o) & 233 & 70.6 \\
\hline & $30-39$ (y.o) & 33 & 10.0 \\
\hline & $40-49$ (y.o) & 46 & 13.9 \\
\hline & $50-59$ (у.о) & 18 & 5.5 \\
\hline & Total & 330 & 100.0 \\
\hline \multirow{6}{*}{ Occupation } & Student & 78 & 23.6 \\
\hline & White Collar & 125 & 37.9 \\
\hline & Civil Servant & 9 & 2.7 \\
\hline & Rsr / Pro. & 8 & 2.4 \\
\hline & Others & 110 & 33.3 \\
\hline & Total & 330 & 100.0 \\
\hline \multirow{7}{*}{ Income } & $\mathrm{x}<1.0 \mathrm{mil}$ won & 137 & 41.5 \\
\hline & $1.0<x<1.5$ mil won & 42 & 12.7 \\
\hline & $1.5<x<2.0$ mil won & 28 & 8.5 \\
\hline & $2.0<x<2.5$ mil won & 17 & 5.2 \\
\hline & $2.5<x<3.0$ mil won & 14 & 4.2 \\
\hline & 3.0 mil won $<x$ & 92 & 27.9 \\
\hline & Total & 330 & 100.0 \\
\hline \multirow{7}{*}{ Experience } & $<1$ month & 70 & 21.2 \\
\hline & $1-6$ months & 84 & 25.5 \\
\hline & $6-12$ months & 65 & 19.7 \\
\hline & $6-18$ months & 40 & 12.1 \\
\hline & $18-24$ months & 11 & 3.3 \\
\hline & $>24$ months & 60 & 18.2 \\
\hline & Total & 330 & 100.0 \\
\hline \multirow{6}{*}{ Waiting time } & within 3 mins & 119 & 36.1 \\
\hline & within 5 mins & 170 & 51.5 \\
\hline & within 10 mins & 20 & 6.1 \\
\hline & within 30 mins & 16 & 4.8 \\
\hline & within 60 mins & 5 & 1.5 \\
\hline & Total & 330 & 100.0 \\
\hline \multirow{6}{*}{$\begin{array}{c}\text { Usage } \\
\text { Experience }\end{array}$} & 1-3 times & 124 & 37.6 \\
\hline & $3-5$ times & 64 & 19.4 \\
\hline & 5-8 times & 59 & 17.9 \\
\hline & 8-10 times & 29 & 8.8 \\
\hline & $>10$ times & 54 & 16.4 \\
\hline & Total & 330 & 100.0 \\
\hline
\end{tabular}

\subsection{Tests of Reliability and Convergent Validity}

To evaluate the measurement model, reliability test was performed at first. Because Cronbach's $\alpha$ values on all variables are over 0.8 , the reliability is satisfied. The result is 
on <Table 4>. With AMOS 23.0, the validity test was conducted by way of confirmatory factor analysis. Its result shows on $<$ Table $5>$. According to the results of confirmatory factor analysis, the model fit is satisfactory with $\chi^{2}=504.783$ $(p=0.000, \quad D F=377), \quad G F I=0.909, \quad A G F I=0.888, \quad N F I=0.927$, $I F I=0.981, C F I=0.980$, RMSEA $=0.032$. With AMOS 23.0, the validity test was conducted by way of confirmatory factor analysis. Its result shows on <Table 5>. According to the results of confirmatory factor analysis, the model fit is satisfactory with $X^{2}=504.783(p=0.000, \quad D F=377), \quad G F I=0.909$, AGFI=0.888, NFI=0.927, IFI=0.981, CFI=0.980, RMSEA $=0.032$. When the values of AVEs between two latent variables were bigger than $r^{2}$, It is evaluated that discriminant validity is satisfied Its result shows on $<$ Table $6>$.

$<$ Table 4> Result of reliability test

\begin{tabular}{|c|c|c|c|}
\hline \multirow{3}{*}{$\begin{array}{c}\text { Taxi-Booking Apps of } \\
\text { e-service quality }\end{array}$} & reactivity & Item no. & Cronbach's $\boldsymbol{\alpha}$ \\
\cline { 2 - 4 } & reliability & 4 & 0.891 \\
\cline { 2 - 4 } & safety & 5 & 0.902 \\
\cline { 2 - 4 } & conveniency & 4 & 0.912 \\
\cline { 2 - 4 } & instant connectivity & 3 & 0.865 \\
\hline \multicolumn{2}{|c|}{ perceived value } & 4 & 0.906 \\
\hline \multicolumn{2}{|c|}{ satisfaction } & 3 & 0.815 \\
\hline \multicolumn{2}{|c|}{ intention of continued use } & 5 & 0.894 \\
\hline
\end{tabular}

$<$ Table 5> Results of confirmatory factor analysis

\begin{tabular}{|c|c|c|c|c|c|c|c|c|}
\hline Variable & Item & f.I. & m.e. & S.E. & C.R. & SMC & AVE & CR \\
\hline \multirow{4}{*}{$\begin{array}{l}\text { reactivity } \\
\text { (react) }\end{array}$} & react1 & .817 & .278 & - & - & .667 & \multirow{4}{*}{0.703} & \multirow{4}{*}{0.905} \\
\hline & react2 & .861 & .240 & .063 & 17.636 & .741 & & \\
\hline & react3 & .818 & .282 & .061 & 16.569 & .669 & & \\
\hline & react4 & .783 & .333 & .062 & 15.669 & .614 & & \\
\hline \multirow{5}{*}{$\begin{array}{l}\text { reliability } \\
\text { (reli) }\end{array}$} & reli1 & .904 & .180 & - & - & .817 & \multirow{5}{*}{0.653} & \multirow{5}{*}{0.902} \\
\hline & reli2 & .825 & .332 & .046 & 20.301 & .681 & & \\
\hline & reli3 & .805 & .363 & .047 & 19.365 & .648 & & \\
\hline & reli4 & .882 & .239 & .044 & 23.141 & .778 & & \\
\hline & reli5 & .592 & .629 & .054 & 12.012 & .351 & & \\
\hline \multirow{4}{*}{ safety } & safety1 & .830 & .309 & - & - & .689 & \multirow{4}{*}{0.731} & \multirow{4}{*}{0.916} \\
\hline & safety2 & .861 & .243 & .054 & 18.824 & .742 & & \\
\hline & safety3 & .818 & .332 & .057 & 17.429 & .668 & & \\
\hline & safety4 & .892 & .183 & .051 & 19.746 & .795 & & \\
\hline \multirow{3}{*}{ conveniency(conve) } & conve1 & .790 & .343 & - & - & .625 & \multirow{3}{*}{0.708} & \multirow{3}{*}{0.879} \\
\hline & conve2 & .866 & .224 & .069 & 15.801 & .750 & & \\
\hline & conve3 & .823 & .278 & .066 & 15.317 & .677 & & \\
\hline \multirow{4}{*}{$\begin{array}{l}\text { instant connectivity } \\
\text { (ic) }\end{array}$} & ic1 & .857 & .249 & - & - & .735 & \multirow{4}{*}{0.719} & \multirow{4}{*}{0.911} \\
\hline & ic2 & .841 & .281 & .053 & 18.742 & .708 & & \\
\hline & ic3 & .843 & .267 & .052 & 18.799 & .710 & & \\
\hline & ic4 & .820 & .307 & .053 & 18.028 & .672 & & \\
\hline \multirow{3}{*}{$\begin{array}{l}\text { perceived value } \\
(\mathrm{pv})\end{array}$} & pv1 & .697 & .627 & - & - & .486 & \multirow{3}{*}{0.615} & \multirow{3}{*}{0.827} \\
\hline & pv2 & .787 & .293 & .073 & 12.358 & .620 & & \\
\hline & pv3 & .855 & .227 & .080 & 12.829 & .731 & & \\
\hline \multirow{5}{*}{$\begin{array}{l}\text { satisfaction } \\
\quad \text { (satis) }\end{array}$} & satis1 & .851 & .246 & - & - & .725 & \multirow{5}{*}{0.660} & \multirow{5}{*}{0.905} \\
\hline & satis2 & .852 & .239 & .052 & 19.151 & .726 & & \\
\hline & satis3 & .827 & .329 & .057 & 18.286 & .684 & & \\
\hline & satis4 & .840 & .272 & .054 & 18.733 & .705 & & \\
\hline & satis5 & .588 & .555 & .059 & 11.396 & .346 & & \\
\hline \multirow{4}{*}{$\begin{array}{l}\text { intention of } \\
\text { continued use } \\
\text { (icu) }\end{array}$} & icu1 & .829 & .279 & - & - & .687 & \multirow{4}{*}{0.733} & \multirow{4}{*}{0.916} \\
\hline & icu2 & .884 & .222 & .058 & 19.446 & .781 & & \\
\hline & icu3 & .850 & .250 & .056 & 18.396 & .722 & & \\
\hline & icu4 & .825 & .295 & .057 & 17.605 & .680 & & \\
\hline
\end{tabular}

\footnotetext{
* f.l. means factor loading, m.e means measurement error
} 
$<$ Table 6> Results of discriminant validity

\begin{tabular}{|c|c|c|c|c|c|c|c|c|}
\hline & react & reli & safety & conve & ic & pv & satis & icu \\
\hline react & 0.703 & & & & & & & \\
\hline reli & 0.226 & 0.653 & & & & & & \\
\hline safety & 0.313 & 0.333 & 0.731 & & & & & \\
\hline conve & 0.447 & 0.241 & 0.252 & 0.708 & & & & \\
\hline ic & 0.161 & 0.271 & 0.160 & 0.266 & 0.719 & & & \\
\hline pv & 0.388 & 0.392 & 0.309 & 0.395 & 0.304 & 0.615 & & \\
\hline satis & 0.319 & 0.337 & 0.227 & 0.334 & 0.286 & 0.386 & 0.660 & \\
\hline icu & 0.316 & 0.399 & 0.225 & 0.310 & 0.398 & 0.554 & 0.393 & 0.733 \\
\hline
\end{tabular}

$<$ Table 7> Hypothesis Testing Results

\begin{tabular}{|c|c|c|c|c|c|}
\hline Route(Hypothesis) & Estimate & S.E. & C.R. & p-value & Result \\
\hline H1-1: Reactivity $\rightarrow$ Perceived value & .225 & .067 & 3.337 & $\star * \star *$ & Accepted \\
\hline H1-2: Reliability $\rightarrow$ Perceived value & .197 & .052 & 3.806 & *** & Accepted \\
\hline H1-3: safety $\rightarrow$ Perceived value & .079 & .058 & 1.360 & .174 & Rejected \\
\hline H1-4: Conveniency $\rightarrow$ Perceived value & .193 & .065 & 2.971 & .003 & Accepted \\
\hline H1-5: instant connectivity $\rightarrow$ Perceived value & .153 & .054 & 2.831 & .005 & Accepted \\
\hline H2-1: Reactivity $\rightarrow$ Satisfaction & .163 & .072 & 2.273 & .023 & Accepted \\
\hline H2-2: Reliability $\rightarrow$ Satisfaction & .138 & .055 & 2.515 & .012 & Accepted \\
\hline H2-3: safety $\rightarrow$ Satisfaction & .017 & .061 & .275 & .783 & Rejected \\
\hline H2-4: Conveniency $\rightarrow$ Satisfaction & .140 & .069 & 2.032 & .042 & Accepted \\
\hline H2-5: instant connectivity $\rightarrow$ Satisfaction & .130 & .057 & 2.273 & .023 & Accepted \\
\hline H3: Perceived value $\rightarrow$ Satisfaction & .165 & .077 & 2.141 & .032 & Accepted \\
\hline H4: Perceived value $\rightarrow$ Intention of continued use & .507 & .070 & 7.285 & 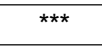 & Accepted \\
\hline H5: Satisfaction $\rightarrow$ Intention of continued use & .205 & .056 & 3.635 & $* \star \star *$ & Accepted \\
\hline
\end{tabular}

*** The corresponding figures path coefficient is also significant at the significance level $(p<0.05)$

$<$ Table 8> Results of mediating effects test by bootstrapping method

\begin{tabular}{|c|c|c|c|}
\hline Path & Direct Effect & Indirect Effect & Total Effect \\
\hline reactivity $\rightarrow$ Perceived Value $\rightarrow$ intention of continued use & .220 & .109 & .329 \\
\hline reactivity $\rightarrow$ Satisfaction $\rightarrow$ intention of continued use & .152 & .032 & .184 \\
\hline reliability $\rightarrow$ Perceived Value $\rightarrow$ intention of continued use & .233 & .115 & .348 \\
\hline reliability $\rightarrow$ Satisfaction $\rightarrow$ intention of continued use & .157 & .033 & .190 \\
\hline safety $\rightarrow$ Perceived Value $\rightarrow$ intention of continued use & .085 & .042 & .127 \\
\hline safety $\rightarrow$ Satisfaction $\rightarrow$ intention of continued use & .017 & .004 & .021 \\
\hline conveniency $\rightarrow$ Perceived Value $\rightarrow$ intention of continued use & .191 & .095 & .286 \\
\hline conveniency $\rightarrow$ Satisfaction $\rightarrow$ intention of continued use & .132 & .028 & .160 \\
\hline instant connectivity $\rightarrow$ Perceived Value $\rightarrow$ intention of continued use & .166 & .082 & .248 \\
\hline instant connectivity $\rightarrow$ Satisfaction $\rightarrow$ intention of continued use & .135 & .028 & .163 \\
\hline
\end{tabular}

\section{Hypothesis Test}

With reference to the table above, it is clearly shown that such criteria and factors are the major characteristics of e-service of taxi call app. Focusing on the hypothesis based on 5 independent variables like reactivity, reliability/ trustworthiness, safety/security, conveniency, instant connectivity, 2 mediators like satisfaction and perceived value, 1 dependant variable like intention on continued use, the results are as follows. All hypotheses except two ones( $<\mathrm{H} 1-3>,<\mathrm{H} 2-3>)$ are Rejected. The results of empirical test are as follows.

\section{Mediating Effects}

There were two kinds to test mediating effects. Namely they were bootstrapping method and sobel test. At this paper, bootstrapping method verified the mediating effects. The results of mediating effects test shows on $<$ Table $8>$. 


\section{Conclusions and Limitations}

The results of this study are as follows. First, all variables of e-service quality(reactivity, reliability/trustworthiness, conveniency, instant connectivity) except safety among taxi-booking apps make influences on perceived value. Second, e-service quality(reactivity, reliability/trustworthiness, conveniency, instant connectivity) except safety among taxi-booking apps make influences on satisfaction. Third, perceived value makes influence on satisfaction. Fourth, perceived value makes influence on intention of continued use. Fifth, satisfaction makes influence on intention of continued use.

But this study has some limitations. First, 5 variables are very limited. more valuable variables are need to test with this model. Second, this study was conducted only in China with questionnaire site. So there may be possible to the representatives. To use this model for better analysis and application abroad, more characteristics and strategic factors should be considered. For instance, the local culture of a particular country, attributes for different environment etc.

This research is developed by taking the use of taxi-calling apps users as the center; although trying to achieve innovative and precise on previous studies reading, theoretical model building and questionnaire design and analysis, there are still some limitations due to the limitations on objective conditions such as human and material resources. So, this need some more supplements to be a complete article. The respondents shall be further expanded. Most of the respondents of this research are during 20-29 years' old, with the main groups of students and white collars, with multiple differences such as territories, income and others. Therefore, it is necessary to expand the territory and income ranges in the future studies, to include respondents in a more overall way, in order to conduct more overall research on the use of taxi-calling apps. The hypothetical influencing factors: This research proposes hypothesis mainly according to taxi-calling apps of e-service quality, and the two model theories have been tested by predecessors repeatedly. The researches in the future can start with different theories and practical experience, to promote more diversified hypothetical influencing factors, to make the promotion strategies formulated in a more accurate and perfect way. It is needed to adjust these results to other countries including Korea. To prove this, it is necessary to make empirical study world-widely.

\section{References}

Ahn, M. J. (2013). A Study on the Acceptance Factors and Gratification of the early Smart TV Users. Master's Dissertation, Sogang University.
Bak, K. N., Jeong, G. H., \& Lee, H. Y. (2012). Acceptance Factors of Mobile Applications: Based on the Perceived Risk and Two-Sided Network Effects. Electronic Commerce Study the Internet, 12(3), 207-235.

Choi, M. S. (2011). A study on the influence of factors such as personal innovativeness, social influence and user interface on smart phone acceptance: Based on an expanded technology acceptance model. Master's Dissertation, Ewha Womans University.

Gu, F. F. (2014). A study on the continuous use of applications among Korean and Chinese smartphone users. Master's Dissertation, Hanyang University.

Gwak, Y. S (2013). A study on the factors affecting the continuous intention of using cloud-based note-taking application. Master's Dissertation, Yonsei University.

Han, J. S. (2014). Understanding Travel-related Mobile Application Users' Continuance Intention: An Extension of the Expectation-Confirmation Model. Master's Dissertation, Kyung Hee University.

Han, P. G., Bak, J. S., Jeon, B. H., \& Gang, B. G. (2010). Study of on the mobile application factors. The Service Journal of Korea, 19(3), 65-82.

Hu, C. G. (2012). Satisfaction Study on Factors Affecting on: Web applications and use of smartphone application slightly under perform versus native applications. Master's Dissertation, Korea University.

Jang, S. H. (2014). An investigation of factors affecting consumer intention to use branded app: Focused on technology acceptance model(TAM). Master's Dissertation, Korea University.

Jeon, J. M. (2014). Mobile application service of convenience, perceived value, customer satisfaction, intention in relation to action research - Focusing on airlines. Master's Dissertation, Kyonggi University.

Jeon, S. H. (2012). A study on the effect of user innovativeness and product characteristic on repurchase intention of smart device. Doctorial Dissertaion, KonKuk University.

Jeon, S. H., Mun, J. B., \& Yu, W. J. (2014). Study on the Factors Influencing the User Satisfaction and Cost Satisfaction of Smart Devices. The e-business Studies, 13(1), 3-24.

Jeong, S. M. (2014). Reward continuous A Study on the factors that affect the intended use of apps. Master's Dissertation, Sogang University.

Jin, Y. (2012). A study on continuous acceptance factors of tablet PC based on TAM model: Focus on Chinese consumers. Master's Dissertation, Korea 
University.

Kim, D. Y. (2011). A Study On the Improvement of the domestic in producing area organizations According to the change retail environment. The International Journal of Industrial Distribution \& Business, 2(2), 5-14.

Kim, J. H. (2010). A study on the acceptance intention for smart phone: Using an extended TAM. Master's Dissertation, Konkuk University.

Kim, J. S., \& Jung, S. Y. (2016). A Study on Behavioral Intention of $\mathrm{O} 2 \mathrm{O}$ Service Using the Model of Goal-Directed Behaviour. Journal of the Korean Society for Supply Chain Management, 16(2), 11-22.

Kim, M. J. (2015). The effect of smart phone mobile banking usability and perceived usefulness on continued use intention. Master's Dissertation, Hongik University.

Kim, S. H. (2012). Smart $v$ http in the environment orthotectic including via streaming video services for content encryption techniques. Master's Dissertation, Soongsil University.

Kim, S. S., Han, G. S., Kim, B. S., Bak, S. Y., \& An, S. G. (2011). An Empirical Study on Users' Intention to Use Mobile Applications. Korea Association Scientific Journals, Information Technology, 9(8), 213-228.

Lee, D. G. (2011). A Study An Empirical Study on the Prediction of Potential Consumers' Intention to Use Smart TV. Doctorial Dissertaion, Chonnam National University.

Lee, D. Y. (2012). A study on Why Consumers UseAirline Applications for Smart Phones. Master's Dissertation, Korea Aerospace University.

Lee, E. M. (2014). A Study on the Factors Affecting Reuse Intention of Mobile Application. Master Thesis, ChonBuk National University.

Lee, J. A. (2014). Influence of motivation for using smart phone application and innovation/congruence on application use and substitution for other media/living equipment. Master's Dissertation, Sogang University.

Lee, J. Y.. \& Eune, J. Y. (2013). A Study on acceptance factors of smart TVs: Focusing on UX, UI Archives of Design Research, 26(1), 287-311.

Lee, S. H., \& Kim, D. T. (2006). The Effects of Ubiquitous Attributes of Mobile Contents on Consumer Acceptance. The Journal of Business Administration, 19(20), 651-678.

Lee, S. K., \& Kim, J. H. (2009). A Study on the Utilization of Mobile Phone Contents, Recognized Risks, and Mobile Phone Addiction. Media of
Scientific Research, 9(4), 540-575.

Lee, S. Y. (2012). Promoting the Museum Communication Through Smart Mobile Applications. Master's Dissertation, Kookmin University.

Li, Q. Z., \& Lee, J. H. (2017). The Influential Relation on Sharing Economy and Consumer Traits. The International Journal of Industrial Distribution \& Business, 8(6), 75-86.

No, J. G. (2013). A Study on Users' Participation Intention Influenced by Users' Perceived Usefulness \& Perceived Ease of Use of Smartphone Radio Application. Master's Dissertation, Seoul National University.

Park, H. S., \& Kim, S. H. (2011). The attribute is perceived value of smartphone applications, services, user satisfaction, impact on intended and recommendations. Korea Management Information Society, the Proceedings of the Symposium, 2011(1), 78-84.

Pyo, J. N. (2012). The Affecting Factors on the Usage of Smart Phone Application: The case of Kakao Talk. Master's Dissertation, Dongguk University.

Sang, H. G. (2014). A Study on the Influence of Using Intention by E-Government's G4C Smart Application Service Characteristics: Focused on the Comparison between Korea and China. Master's Dissertation, Kongju University.

Shao, L., Zhang, L., \& Yu, X. H. (2017). Empirical Study of Dynamic Chinese Corporate Governance Based on Chinese-listed Firms with A Panel VAR Approach. The International Journal of Industrial Distribution \& Business, 8(1), 5-13.

Tian, X. F., Wu, R. Z., \& Lee, J. H. (2017). Use Intention of Chauffeured Car Services by $\mathrm{O} 2 \mathrm{O}$ and Sharing Economy. Journal of Distribution Science, 15(12), 73-84.

Wang, M. (2015). A comparative Study on Affecting Factors of Smart Phone paid/free Application Use's continuance Intention. Jeonnam. Master's Dissertation, Chonnam National University.

Wu, R. Z., \& Lee, J. H. (2017). The Comparative Study on Third Party Mobile Payment between UTAUT2 and TTF. Journal of Distribution Science, 15(11), 5-19.

Wu, R. Z., \& Lee, J. H. (2017). The Use Intention of Mobile Travel Apps by Korea-Visiting Chinese Tourists. Journal of Distribution Science, 15(5), 53-64.

Wu, R. Z., \& Lee, J. H. (2016). The Effects of Repurchase Intention by Social Commerce Traits and Consumer's Traits in China. Journal of Distribution Science, 14(5), 97-106. 
Yoon, J. H. (2010). The Impact of User Interface Types Characteristics on the Information Media Usage Behavior. Gwallihak Information Bulletin, 27(3), 53-66.

Yu, H. Y. (2013). Brand apps the properties of user satisfaction and on product gumaeui. Master's
Dissertation, Jeju National University.

Yu, J. H. (2013). A study on the Influence of Customer Satisfaction by Smartphone-based Game Applications. Master's Dissertation, Dongguk University. 